\title{
DEFICIÊNCIAS FÍSICAS: BARREIRAS NA APRENDIZAGEM E ADAPTAÇÕES DO AMBIENTE ACADÊMICO
}

Eliene Germana Pires ${ }^{1}$

\section{RESUMO}

Esta pesquisa identificou que as principais barreiras na aprendizagem dos alunos deficientes físicos são: físicas, atitudinais e de comunicação em razão de muitas escolas ainda não contarem com estruturas físicas adaptadas e profissionais capacitados para lidar com deficiências diversas. Notou-se que há a necessidade de adaptações do ambiente acadêmico para superar as barreiras que interferem no processo de ensino-aprendizagem do acadêmico com deficiência física tais como: construção de rampas de acessos, banheiros para cadeirantes, contratação de redução do preconceito e tecnologias assistivas. Mediante uma pesquisa descritiva que teve o questionário, mediado por uma entrevista, como instrumento de coleta de dados, notou-se que o não oferecimento de condições de acesso, permanência, sucesso e garantia do padrão de qualidade desse processo incidem sobre as dificuldades de aprendizagem, nas notas baixas e no processo de interação destes alunos. Este trabalho serviu de norte para a eliminação de barreiras físicas, atitudinais e de comunicação da aprendizagem da pessoa com deficiência.

Palavras-chave: processo ensino-aprendizagem, deficiência física, barreiras físicas, atitudinais e de comunicação.

\section{ABSTRACT}

This research identified that the main barriers to the learning of disabled students are: physical, attitudinal and communication because many schools do not yet have adapted physical structures and trained professionals to deal with various disabilities. It was noted that there is a need for adaptations of the academic environment to overcome the barriers that interfere in the teaching-learning process of physically disabled students, such as: building access ramps, wheelchair users, contracting teachers of Libras and Braille, Reduction of prejudice and assistive media. Through a descriptive research that had the questionnaire, mediated by an interview, as a data collection instrument, it was

\footnotetext{
${ }^{1}$ Mestranda em Educação pela Unilogos - Email: elienegermanapires@yahoo.com.br
} 
noticed that the non-availability of conditions of access, permanence, success and guarantee of the quality standard of this process affect learning difficulties, Low grades and the interaction process of these students. This work served as the north for the elimination of physical, attitudinal and communication barriers of the learning of the person with disability.

Key words: teaching-learning process, physical disability, physical, attitudinal and communication barriers.

\section{INTRODUÇÃO}

Este pretende identificar as principais barreiras na aprendizagem de alunos deficientes físicos e as necessidades de adaptações do ambiente acadêmico para superar essas barreiras que interferem no processo de ensinoaprendizagem do acadêmico com deficiência física.

A construção desta pesquisa se justifica em razão da pesquisadora ser acadêmica com deficiência ${ }^{1}$ física e encontrar inúmeras dificuldades no ambiente acadêmico, tanto de ordem física (dificuldade de locomoção) e de aprendizagem ${ }^{2}$. Ainda pelo fato de que a deficiência física ser um processo de construção de uma verdadeira sociedade inclusiva ${ }^{3}$ e integrativa ${ }^{4}$ como afirma Sassaki (1997).

\footnotetext{
${ }^{1}$ Quando em consequência de algum mal, o ser humano é vítima de certo impedimento de ordem física, instala-se uma deficiência. Esta deficiência poderá levar ou não a uma incapacidade: uma situação de desvantagem. Em outras palavras, a deficiência está relacionada com a perda ou limitação de oportunidade de participação da vida comunitária em condições de igualdade com as demais pessoas (Resolução 48/96, ONU). Já a incapacidade está relacionada com a "redução", "restrição" efetiva e acentuada, com a oportunidade de inclusão social, requerendo equipamentos especiais. Quando nasce uma criança deficiente, a estrutura e a dinâmica de uma família são alteradas: a família tem que aprender a sobreviver à situação, buscar ajuda, se ajustar a situação e se separar, quando preciso (MILLER, 1995).

2 Por aprendizagem se entende as modificações produzidas pelo Sistema Nervoso Central (SNC), mais ou menos permanente, que se traduzem por uma modificação funcional ou comportamental, permitindo a melhor adaptação do indivíduo ao seu meio como resposta a uma solicitação interna ou externa, isto é, frente à realização de uma tarefa ou resolução de um problema. Em outras palavras, quando um estímulo já é conhecido do SNC, desencadeia uma lembrança; quando o estímulo é novo, desencadeia uma mudança no organismo, e esta mudança sempre será influenciada pelo ambiente e a tarefa de quem a realiza (RELVAS, (2009). 3 Processo que visa tornar aptas $e$ inclusas todas as crianças na comunidade, independentemente de suas diferenças ou dificuldades individuais. Procura organizar fundamentalmente o processo de ensino e aprendizagem, garantindo o acesso, a permanência, o sucesso e o padrão de qualidade deste processo. Seu fulcro está na sociedade, que deve se preparar para que ninguém fique fora deste processo (BRASIL, 1994).

${ }_{4}$ Processo de incorporar física e socialmente dentro da sociedade as pessoas que estão segregadas e isoladas das outras. Significa ser um membro ativo da comunidade, vivendo onde os outros vivem, vivendo como as demais e tendo os mesmos privilégios e direitos que os cidadãos não deficientes. Seu fulcro esta na preparação do deficiente para aceitar a sociedade como ela é: se adaptar (FARIAS, 1991).
} 
Para o autor refletir sobre os cuidados com a linguagem ${ }^{5}$ é fundamental, uma vez que por meio dela, voluntária ou involuntariamente, se expressa 0 respeito ou a discriminação em relação às pessoas com deficiências, tornandose barreiras atitudinais ou de comunicação ${ }^{6}$.

Examinar reflexivamente, com atenção, é o que se propôs tratar esta pesquisa. $O$ assunto é importante porque a educação ${ }^{7}$ para a diversidade tem como significado um desafio a ser superado, que no caso da pesquisa foi à identificação de como o aluno encara o processo de ensino-aprendizagem e como faz para superar as barreiras a ele impostas pela sua própria limitação física. A ênfase dada foi no esforço coletivo do professor, dos alunos e da instituição em responder e superar os desafios, adaptando-se ${ }^{8}$ a eles.

Este assunto já foi tratado por diversos autores entre eles Carmo (1991), Lovato (2008), Rozick (2010), Sassaki (1997) e Mantoan (1997). Para esses autores, a deficiência física e a aprendizagem dos alunos estão intimamente relacionadas, uma vez que ainda vivemos em uma sociedade historicamente marcada pelo preconceito e discriminação. É preciso construir uma sociedade mais justa, mais inclusiva, fortalecer dentro das instituições e na sociedade em geral o respeito pela diversidade, o respeito aos direitos humanos em geral.

O estudo divide-se em: introdução, revisão da literatura, materiais e métodos, resultados, discussão dos resultados e considerações finais. 0 mesmo é de extrema importância, tendo em vista que visa contribuir para a ampliação dos debates sobre a participação das pessoas com deficiência na sociedade e na escola, enfatizando as barreiras físicas e intelectuais, de atitude e comunicação que dificultam sua plena participação de maneira equitativa na sociedade.

\footnotetext{
${ }^{5}$ A linguagem possui um código abstrato com regras governando a sua construção, uso e entendimento. Possui também uma estrutura organizacional própria, uma arbitrariedade na sua composição e a possibilidade de gerar novos sentidos (McCORMICK e SCHIEFELBUSCH, 1984).

${ }^{6} \mathrm{~A}$ comunicação é mais que produzir um entendimento na linguagem. Ela é a troca de ideias e intenções (McCORMICK e SCHIEFELBUSCH, 1984).

${ }^{7}$ A educação favorecerá a igualdade de oportunidade e a equidade, ou pelo contrário, será um fator de seleção, marginalização e exclusão? Este é o primeiro desafio do próximo século. Tratase de responder á pergunta: seremos capazes de respeitar a diversidade? (IMBERNÓN, 2000). ${ }^{8}$ Por adaptação entende-se a complexa inter-relação entre as forças do sujeito, do ambiente e da tarefa da educação. O serviço da educação é procurar os meios, modos e formas de se atingir a aprendizagem: tarefa do professor (FARIAS, 2003).
} 
Desse modo, podemos distinguir essencialmente quatro condições que foram satisfeitas na proposição de uma explicação que validou o estudo, as quais não necessariamente ocorreram de modo sequencial, mas sim de forma imbricada, de acordo com Humberto Maturana e Francisco Varela (2001), no livro A árvore do conhecimento: In Relatório de Pesquisa de Farias (2006).

\begin{abstract}
Descrição do fenômeno explicado, de maneira aceitável para a comunidade de observadores, ou seja, eliminação de barreiras físicas, atitudinais e de comunicação em função das respostas dos alunos no instrumento de investigação.

Hipótese explicativa do estudo: as barreiras arquitetônicas, atitudinais e de comunicação impedem a plena participação das pessoas com deficiência tanto na sociedade, quanto no contexto acadêmico.

Houve dedução a partir da hipótese, de outros fenômenos tais como: ausência de políticas públicas ${ }^{9}$ voltadas para a superação destas barreiras.

E, a falta de estrutura física e pedagógica nas escolas e também nas universidades para atender alunos com deficiência.
\end{abstract}

Esse ciclo de quatro componentes não é estranho ao nosso modo cotidiano de pensar, como afirma Maturana e Varela (2001). O que se pretendeu foi ser consistente e explícito em relação a cada uma das etapas, e deixar um registro documentado para outros estudos e mostrar que a deficiência é apenas uma limitação física que não incide nos aspectos cognitivos, portanto, não devem ser considerada como barreira para a plena participação social.

Nesse sentido, o objetivo deste estudo foi identificar as principais barreiras enfrentadas pelos alunos com deficiência física no ambiente acadêmico e como estas interferem no processo ensino-aprendizagem. Especificamente se quis: identificar as principais barreiras enfrentadas pelos alunos com deficiência física no ambiente acadêmico e como estas interferem no processo de ensinoaprendizagem, mediante um instrumento de coleta de dados; analisou-se o processo ensino-aprendizagem dos alunos com deficiência física numa escola pública estadual de Avelinópolis - Go no qual se procurou compreender a perspectiva dos professores em relação as barreiras que interferem no processo ensino aprendizagem da pessoa com deficiência.

\footnotetext{
${ }^{9}$ Por políticas públicas se entende um elenco de ações e procedimentos que visam à resolução pacífica de conflitos em torno da alocação de bens e recursos públicos, sendo que os personagens envolvidos neste conflito são denominados atores políticos (BRASIL, 1994).
} 


\title{
REVISÃO DA LITERATURA
}

\section{Retrospecto da Educação Especial no Brasil}

Para melhor compreender a trajetória educacional das pessoas com deficiência, discorremos sobre as fases que permeiam a Educação Especial. No intuito de mencionar suas caracteristicas, associada a discussão sobre seus principais aspectos e o que desencadeou cada fase na vida das pessoas com necessidades educacionais especiais.

Conforme Sassaki (1997) em um primeiro momento houve a fase de Negligência / Exclusão, na qual durante muito tempo as pessoas que possuíam algum tipo de deficiência eram tidas como indignas, rejeitadas, abandonadas, ignoradas, perseguidas e exploradas.

Neste prisma Rosa (2003, p.72) afirma que:

\begin{abstract}
A primeira delas corresponde ao período anterior ao século XIX, chamada de "fase da exclusão", na qual a maioria das pessoas com deficiência e outras condições excepcionais era tida como indigna da educação escolar. Nas sociedades antigas era normal o infanticídio, quando se observavam anormalidades nas crianças. Durante a Idade Média a Igreja condenou tais atos, mas por outro lado, acalentou a ideia de atribuir a causas sobrenaturais as anormalidades de que padeciam as pessoas, explicando-as como punição, em decorrência de pecados cometidos. Assim, as crianças que nasciam com alguma deficiência eram escondidas ou sacrificadas.
\end{abstract}

Portanto, nessa fase as pessoas com necessidades especiais não recebiam nenhuma atenção em relação à educação e outros serviços. As pessoas com deficiências eram totalmente excluídas pela sociedade, os mesmos eram ignorados, explorados, rejeitados e/ou sacrificados; pois eram considerados "possuídas por maus espíritos ou vítimas da sina simbólica e feitiçaria". (JÖNSSON, 1994, p.61)

Esse período perpetuou até meados do século XVII, fundamentado nos principios das sociedades greco-romanas; que valorizavam a perfeição e não aceitavam quem fosse diferente desse perfil. Por esse motivo, era muito comum o infanticídio, muitos por meio do costume de jogar essas crianças de precipícios. Já o abandono, caso esses nascituros fossem advindos de famílias ricas,era algo frequente. 
No século XIX, com o advento do Cristianismo, a igreja que pregava a caridade e humildade, passou a condenar tais atitudes e os deficientes passaram a ser vistos e tratados pela sociedade como pessoas que tinham diferenças.

Teve início a denominada fase de Segregação/Institucional; na qual houve algumas mudanças nos conceitos sociais como cita Silva (2013, p.66) "Nessa "fase" percebe-se uma compreensão maior do processo de deficiência e, portanto, é necessário dar um atendimento distinto ao "diferente", porém, ele ainda não é aceito no meio social, continua sendo um "estorvo"(...)".

Destarte, houve uma mudança na concepção a cerca da produtividade destas pessoas. Sendo criadas as primeiras escolas especiais como afirma Sassaki (1997, p. 112):

No início do século XX surgiram também escolas especiais, assim como centros de reabilitação e oficinas protegidas de trabalho, pois a sociedade começou a admitir que pessoas deficientes poderiam ser produtivas se recebessem escolarização e treinamento profissional.

Portanto a Educação Especial, para crianças com deficiência, era desenvolvida por meio de instituições voluntárias, em sua maioria religiosa, sem nenhuma participação do governo, porém com sua permissão. E grande parte dessas crianças e adolescentes passavam a vida inteira nessas instituições, onde eram realizadas atividades básicas de vida diária associada a inibição de alguns comportamentos inadequados ao convívio social.

$\mathrm{Na}$ tentativa de minimizar as barreiras criadas entre pessoas com deficiência e sem deficiência, teve inicio a terceira fase intitulada fase da Integração. E esta teve início na segunda metade do século XX. Um fato marcante que caracterizou essa fase, foi a tentativa de incluir os alunos com deficiência nas escolas regulares de ensino.

Até o surgimento desta nova concepção os educandos com deficiência tinham o direito de frequentar apenas as escolas especiais, pois segundo o discurso da época somente estas instituições possuiam profissionais qualificados para lidar com essa clientela atípica.

Contudo, foram surgindo alguns movimentos sociais que almejavam um tratamento igualitário para todos. Focando na necessidade de se instituir classes especiais dentro das escolas comuns, o que segundo Sassaki (1997 apud CHAMBERS e HARTMAN, in JONSSON,1994, p.62) 
(...) não ocorreu por motivos humanitários e sim para garantir que as crianças deficientes não "interferissem no ensino" ou não "absorvessem as energias do professor" a tal ponto que o impedissem de instruir adequadamente o número de alunos geralmente matriculados numa classe.

No início dos anos 70 surgiram então, as classes especiais dentro de escolas comuns. Para tanto, eram realizados testes de inteligência, com 0 objetivo de selecionar crianças com potencial acadêmico. Para que fossem inseridas nas escolas, com o intuito de acabar com a exclusão.

Nesse período, foi utilizado em demasia os testes de inteligência que elegiam quais crianças ou adolescentes poderiam frequentar as escolas comuns, desde que, se adaptassem ao currículo institucional. Queriam que essas pessoas acometidas de deficiências fizessem um esforço para integrarem a sociedade a qual pertenciam.

No inicio da implantação desse processo houve muita resistência e consequentemente dificuldade por parte das instituições de ensino. Uma vez que, as mesmas não se sentiam preparadas para atender esses educandos na rede regular de ensino. Tendo que, em algumas situações, modificar seu funcionamento para incluir todos os discentes. Contudo, após diversos estudos costatou-se que essa prática implica benefícios não somente para o aluno antes excluído e sim para toda comunidade escolar e social, com o aval novamente de Stainback \& Stainback (1999, p. 21) para ratificar essa informação:

\begin{abstract}
Educando todos os alunos juntos, as pessoas com deficiência têm oportunidade de preparar-se para a vida na comunidade, os professores melhoram suas habilidades profissionais e a sociedade toma a decisão consciente de funcionar de acordo com o valor social da igualdade para todas as pessoas, com os conseqüentes resultados de melhoria da paz social.
\end{abstract}

Observa-se que a prática da inclusão nas escolas, precisa de métodos diferenciados que consigam abranger a todos os alunos, uma vez que, a educação é direito de todos.

De acordo com Centro Nacional de Reestruturação e Inclusão Educacional (1994, p. 12)

(...) provisão de oportunidades equitativas a todos os estudantes, incluindo aqueles com deficiências severas, para que eles recebam serviços educacionais eficazes, com os necessários serviços suplementares de auxílios e apoios, em classes adequadas á idade em 
escolas da vizinhança, a fim de prepará-los para uma vida produtiva como membros plenos da sociedade.

A partir desta nova perspectiva as crianças com necessidades educacionais especiais, passaram a serem vistas pela sociedade, como cidadãos que possuem os mesmos direitos de qualquer outra pessoa, como 0 direito de estudar, trabalhar e conviver em sociedade.

\footnotetext{
Princípio fundamental da escola inclusiva é o de que todas as crianças devem aprender juntas, sempre que possível, independentemente de quaisquer dificuldades ou diferenças que elas possam ter. Escolas inclusivas devem reconhecer e responder às necessidades diversas de seus alunos, acomodando ambos os estilos e ritmos de aprendizagem e assegurando uma educação de qualidade à todos através de um currículo apropriado, arranjos organizacionais, estratégias de ensino, uso de recurso e parceria com as comunidades (SALAMANCA, 1997, Item 7, p.5).
}

Ao comparar esta fase com as demais, mencionadas anteriormente, notase que nela existe uma proposta realmente voltada para as necessidades e potencialidades dos alunos com deficiência.

Contudo, a inclusão escolar viabilizou também, a inclusão social, pois é por meio da mesma que as crianças adquirem contato umas com as outras aprendendo juntas e começam a se sentir inserida e acolhidas na sociedade.

Além deste fato, a inclusão permite que as pessoas com deficiência se sintam inseridas na sociedade tendo os mesmos direitos que os demais. Para tanto, faz-se necessário envolver diversos segmentos da sociedade, pois juntos podemos desenvolver ações de forma a efetivar um ensino de qualidade para os educandos com necessidades educacionais especiais.

\section{Carta de Goiânia: um documento feito por educadores de Goiânia sobre a Inclusão}

A Carta de Goiânia (Anexo) é fruto de um encontro realizado por educadores da capital goiana onde os mesmos, pautados no aparato legal da Educação Inclusiva, firmaram compromisso com a educação de educandos que têm necessidades educativas especiais.

Logo de início encontra-se referência aos objetivos do referido encontro. 


\begin{abstract}
A IV Conferência Brasileira de Educação, ao propor princípios básicos a serem inscritos na Constituição, tem presente que o país enfrenta graves problemas sociais e econômicos, de natureza estrutural, que entravam a efetiva democratização do conjunto da sociedade. Tem presente, também, que o não enfrentamento urgente de tais problemas acarretará o comprometimento da viabilização das políticas sociais, especialmente da política educacional (CARTA DE GOIÂNIA, 1986, p. $5)$.
\end{abstract}

O teor da carta em questão é trazer ao centro alguns aspectos envolvendo a Educação Inclusiva, tais como as políticas públicas que já estão sendo implementadas no Estado de Goiás para potencializar essa modalidade. Ao encerrar o manifesto pautados nas políticas públicas e legislações inclusivas, os três mil professores

que o assinam reiteram a necessidade de se elaborar uma nova Lei de Diretrizes e Bases a qual se concretizou em 1996 com a LDB n. 9394/96 que traz referências importantes não somente para essa modalidade, mas para a o sistema educacional de um modo geral.

\title{
DEFICIÊNCIA FÍSICA
}

O termo deficiência física tem sido utilizado por vários autores, tendo em vista que a história de diversas sociedades descreve pessoas com deficiências. Siqueira (2009) relata exemplos de pessoas deficientes desde os mais remotos tempos, se reportando inclusive à mitologia grega e romana. "No entanto, os deficientes passaram a receber maior atenção somente a partir a II Guerra Mundial, com a volta dos veteranos, muitos deles com deficiências diversas causadas por ferimentos." (SILVA, 2009, p. 12).

A International Classification of Functioning, Disability and Health ${ }^{10}$ (ICIDH) propõe uma classificação da conceituação de deficiência que pode se relacionar a vários aspectos da saúde e da doença, utilizando um referencial específico para a área.

De acordo com Maciel (2000), o ICIDH expõe com clareza, abrangência e hierarquia de intensidades, uma escala de deficiências com níveis de dependência, limitação e seus respectivos códigos, propondo que sejam utilizados com a Classification International Disability (CID) pelos serviços de medicina, reabilitação e segurança social.

\footnotetext{
${ }^{10}$ Classificação Internacional de Funcionalidade, Incapacidade e Saúde.
} 
O ICIDH segundo Hall (1995, p. 18) classifica estas categorias da seguinte maneira:

Deficiência: perda ou anormalidade de estrutura ou função psicológica, fisiológica ou anatômica, temporária ou permanente. Incluem-se nessas a ocorrência de uma anomalia, defeito ou perda de um membro, órgão, tecido ou qualquer outra estrutura do corpo, inclusive das funções mentais. Representa a exteriorização de um estado patológico, refletindo um distúrbio orgânico, uma perturbação no órgão. Incapacidade: restrição, resultante de uma deficiência, da habilidade para desempenhar uma atividade considerada normal para o ser humano. Surge como consequência direta ou é resposta do indivíduo a uma deficiência psicológica, física, sensorial ou outra. Representa a objetivação da deficiência e reflete os distúrbios da própria pessoa, nas atividades e comportamentos essenciais à vida diária. Desvantagem: prejuízo para o indivíduo, resultante de uma deficiência ou uma incapacidade, que limita ou impede o desempenho de papéis de acordo com a idade, sexo, fatores sociais e culturais Caracteriza-se por uma discordância entre a capacidade individual de realização e as expectativas do indivíduo ou do seu grupo social. Representa a socialização da deficiência e relaciona-se às dificuldades nas habilidades de sobrevivência.

Ao analisar estas categorias Hall (1995) chama atenção para fragilidade do modelo denominado de incapacidade, quando se referem à pessoas adultas com múltiplas deficiências. O autor comenta que a utilização da ICIDH poderia trazer abordagens científicas e práticas, sobretudo, no que diz respeito à qualidade de vida destas pessoas. Tal abordagem favoreceria uma "maior aceitação do seu registro como deficiente e uma melhor provisão de serviços. Enfatizou a importância de repensar, além da terminologia, atitudes e de se certificar que os novos termos estão sendo aceitos e compreendidos (HALL, 1995, p. 23).

A deficiência física se insere no quadro das condições crônicas às quais os princípios preconizados pelo Sistema Único de Saúde (SUS) implicam atenção, sendo crescente a sua importância na Saúde Pública, anunciada pelas iniciativas governamentais de descentralização dos serviços, os quais incluem reabilitação, por força da criação dos Núcleos de Apoio a Saúde da Família NASF.

De acordo com Martins e Barsaglini (2011) as pessoas com deficiência física enfrentam para ampliar suas relações sociais, constituindo novos vínculos através da participação em grupos sociais extrafamiliares, decorrentes, principalmente, da dificuldade de locomoção. Estas limitações têm impacto direto 
sobre o nível e a diversidade de participação que essas pessoas podem desenvolver na sociedade.

Além das barreiras no âmbito das relações sociais, as pessoas com deficiência física também enfrentam barreiras físicas. Por isso a importância da acessibilidade.

\section{DEFICIÊNCIA E APRENDIZAGEM}

Para compreender a relação entre aprendizagem e deficiência, alguns autores partem do desenvolvimento motor, associando-o à cognição.

Segundo Connel (1991, p. 72),

A cognição está sempre envolvida no processo da aprendizagem motora e que tal compreensão poderá ajudar o professor a entender por que se verificam comportamentos motores tão pobres. A programação e controle das ações motoras são funções da cognição. A maior capacidade de elaboração, planejamento, raciocínio e outras funções do domínio cognitivo terão influência direta sobre o comportamento motor. Ao mesmo tempo, o papel do movimento no desenvolvimento da cognição é vital.

Segundo o autor supracitado, uma habilidade motora envolve a própria qualidade do movimento; envolve principalmente o como fazê-lo.

Ao abordar tal perspectiva, Schimidt (1992) expõe que uma habilidade cognitiva envolve as decisões sobre que movimento fazer; envolve principalmente a seleção do que fazer "Toda habilidade, não importa a quão cognitiva ela possa parecer, exige pelo menos uma resposta motora, e toda habilidade motora exige alguma tomada de decisão anterior" (SCHMIDT, 1992, p. 8). Na perspectiva do autor, são combinações complexas de tomada de decisão e desempenho, de habilidade cognitiva e habilidade motora.

E Tani et. al. (1988) complementando as ideias dos autores relata que "Tanto nas habilidades motoras quanto nas cognitivas, são solicitados mecanismos que captam, processam e transformam as informações para facilitar a organização, o armazenamento e a recuperação dessas informações" (TANI et. al., 1988). 
Ao discutir sobre o envolvimento cognitivo na aprendizagem motora, Connel (1991, p. 125), propõe três fases para a aprendizagem.

\begin{abstract}
A primeira, chamada de fase cognitiva, em que o indivíduo desenvolve uma capacidade de compreensão de tudo o que a tarefa envolve, baseia-se em experiências anteriores e procura nelas elementos que possam ajudar a resolver um problema atual. $\mathrm{Na}$ segunda fase, chamada de fase associativa, o indivíduo depende em parte da atividade mental, pois é nessa fase que ele desenvolve novas respostas, que aos poucos se aproximam daquilo que a tarefa exige. $\mathrm{Na}$ terceira fase, denominada autônoma, o indivíduo é menos dependente das demandas de atenção e domina os elementos da tarefa.
\end{abstract}

Do exposto pelo autor, vale ressaltar que as dificuldades de aprendizagem apresentadas por pessoas com deficiência podem ser decorrentes destas três fases ou não, sendo que em muitos, a deficiência física não altera o processo cognitivo.

Concordando com a ideia de Connel (1991), Gentile (1972) afirma que a aprendizagem motora ocorre em dois estágios: fase de obtenção da ideia de movimento, que é o estágio inicial de aquisição de uma habilidade, e estágio designado como estágio de fixação/diversificação.

Na fase de obtenção da ideia de movimento, a autora descreve 8 áreas envolvidas (meta, subconjunto de estímulos reguladores, atenção seletiva, plano motor, execução da resposta, retroalimentação, processo de decisão e próxima resposta) das quais destacamos a da atenção seletiva. Depois de compreender quais os requisitos da tarefa e de decidir quais as informações relevantes, o indivíduo planeja a resposta (GENTILE, 1972, p. 46).

Assim, deve-se considerar que a aprendizagem constitui-se de uma combinação de ações que envolvem habilidades motoras e cognitivas. Em decorrência disso, qualquer tarefa motora necessita de habilidades cognitivas necessárias para captar qualquer informação sensorial "tomada de decisão, resposta e feedback, e que a alteração em um desses processos (cognitivo ou motor) influenciará na performance do aluno." (GENTILE, 1972, p. 52).

A partir das considerações do autor, pode-se entender que cada pessoa possui atributos diferentes não sendo portando, únicos fatores a influir sobre a 
gravidade de seu comprometimento funcional, isto é, pelo grau de prejuízo funcional de uma deficiência pode variar dependendo da pessoa no momento da avaliação.

\section{MATERIAIS E MÉTODOS}

No processo de buscas pelas evidências empíricas, foi utilizada entrevista com roteiro. Foram coletados dados que permitiram a caracterização social dos participantes.

Neste estudo a análise dos dados foi conduzida através de três fases interativas e contínuas, baseado na proposta de Miles e Huberman (1994), onde primeiro se trabalha a redução dos dados, elaborado em um processo contínuo de seleção, simplificação, abstração e transformação dos dados originários das observações de campo.

Os sujeitos da pesquisa foram dois alunos com deficiência física matriculados numa escola pública situada na cidade de Avelinópolis-Go. Também participaram os professores desses educandos. O Colégio Estadual Professor Alfredo Nasser localiza-se à Avenida Mato Grosso n. 29 - Centro Avelinópolis/Go. A instituição é pública, sendo a mesma administrada pela Secretaria de Estado da Educação de Goiás.

Após a entrevista os dados foram tratados no programa Excel onde foram construídos os gráficos que posteriormente foram comentados à luz do referencial teórico utilizado na pesquisa.

\section{ANÁLISE DOS RESULTADOS}

\section{Análise do questionário dos alunos}

Gráfico 1: Faixa etária 


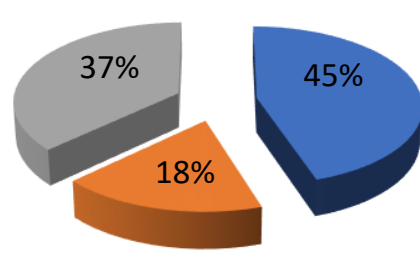

Entre 10 e 15 anos

Entre 15 e 20

anos

Mais de 20 anos

Fonte: Dados da pesquisa

Sobre a faixa etária dos entrevistados, os dados mostram que grande parte deles (45\%) encontra-se na faixa etária entre 10 e 15 anos de idade, 18\% estão entre 15 e 20 anos e $37 \%$ têm mais de vinte anos.

Gráfico 2: Desde quando é portador de deficiência física

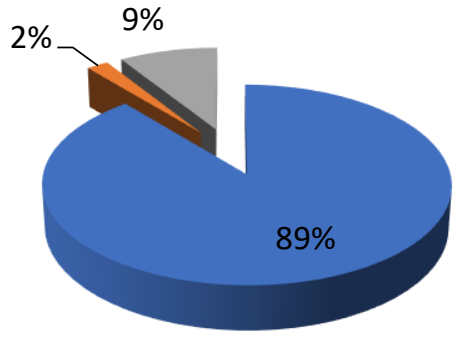

$$
\begin{aligned}
& \text { Desde o } \\
& \text { nascimento } \\
& \text { Depois do } \\
& \text { nascimento } \\
& \text { Não soube } \\
& \text { responder }
\end{aligned}
$$

Fonte: Dados da pesquisa

Ao serem questionados sobre o início da deficiência física, $89 \%$ respondeu que foi desde o nascimento, $2 \%$ disseram que foi depois do nascimento e $9 \%$ não souberam responder.

Ressalta-se que a deficiência física apresentada pelos entrevistados é variada, sendo: Paraplegia (perda total das funções motoras dos membros inferiores); Paraparesia (perda parcial das funções motoras dos membros inferiores); Monoplegia (perda total das funções motoras de um só membro (inferior ou posterior) e Monoparesia (perda parcial das funções motoras de um só membro (inferior ou posterior).

Gráfico 3: Tipo de escola que estudou até o momento 


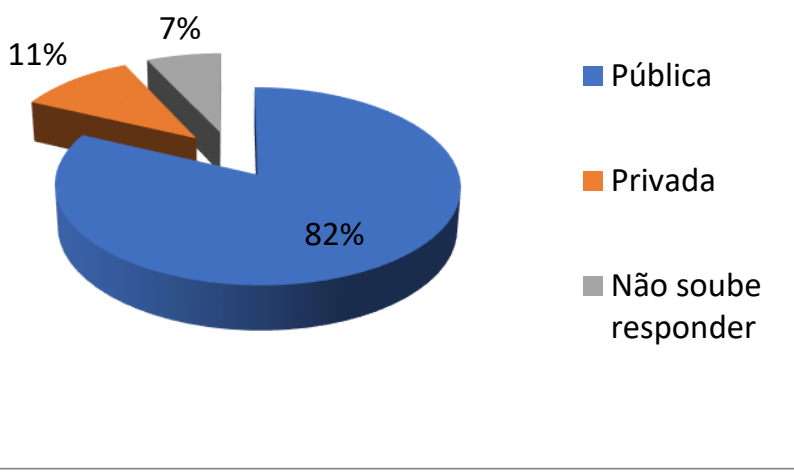

Fonte: Dados da pesquisa

Sobre a origem da escola na qual estudaram ao longo da vida, $82 \%$ responderam que sempre foi na escola pública, $11 \%$ disseram que foi em outra rede e $7 \%$ não souberam responder.

Gráfico 4: Série que estuda

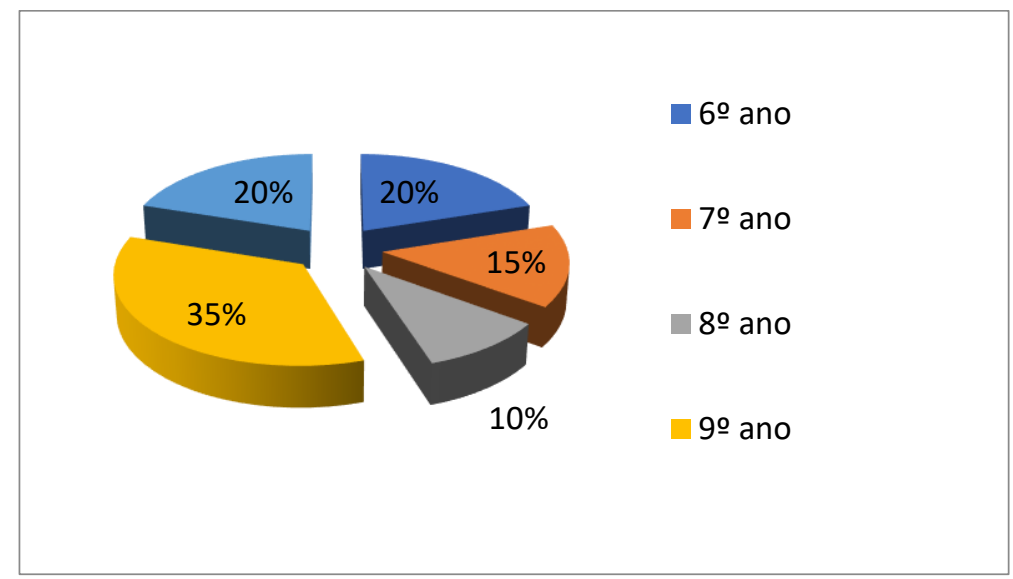

Fonte: Dados da pesquisa

Sobre a série em que estão matriculados, os dados mostram que $20 \%$ estão no $6^{\circ}$ ano, $15 \%$ no $7^{\circ}$, $10 \%$ deles estão no $8^{\circ}$ ano e maior parte (35\%) estão em uma das séries do Ensino Médio.

Gráfico 5: Tem dificuldades de aprendizagem 

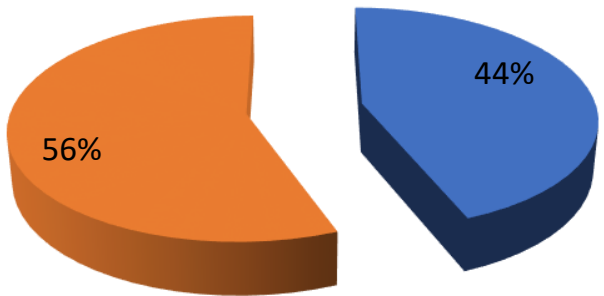

- Sim

Não

Fonte: Dados da pesquisa

Sobre as dificuldades de aprendizagem, os dados mostram índices muito aproximados para sim e para não, sendo respectivamente 44\% e 56\%. Ressaltase que essas dificuldades são de todas as ordens, tanto cognitivas, quanto de linguagem, cálculos entre outras.

Gráfico 6: Principais dificuldades de acesso para chegar até a escola e se movimentar na escola

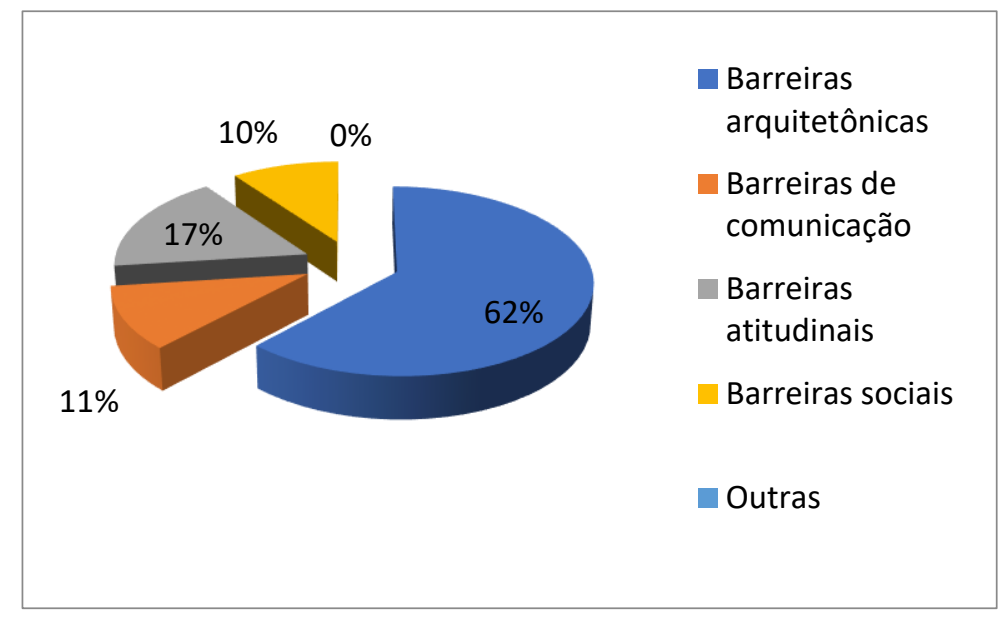

Fonte: Dados da pesquisa

Ao serem questionados sobre as principais dificuldades de acesso para chegar até a escola e se movimentar na escola, os índices maiores (62\%) foram para barreiras arquitetônicas, $11 \%$ disseram que são as barreiras de comunicação, 17\% afirmam que são as barreiras atitudinais,10\% consideram que são sociais e nenhum entrevistado disseque são outros tipos, lembrando que as barreiras arquitetônicas "impostas às pessoas com limitações temporárias, aos idosos e aos portadores de deficiência são formadas por todas 
e qualquer barreira relacionada às construções urbanas ou às edificações" (SIQUEIRA, 29 p. 39).

As barreiras de comunicação envolvem aquela de ordem pessoal, física e semânticas. As primeiras influenciam nas barreiras pessoais certos hábitos falhos na hora de ouvir, envolvendo emoções e outros tipos de sentimentos pessoais. As barreiras físicas ocorrem dentro do ambiente de comunicação. Já as barreiras semânticas referem-se "às limitações e distorções da comunicação feita através de símbolos, como gestos, sinais, etc.,que podem ter diferentes sentidos para cada pessoa, distorcendo o real significado da mensagem inicial" (CHIAVENATO, 2009).

Sobre as barreiras atitudinais Garcia $(2012$, p. 1) pontua que:

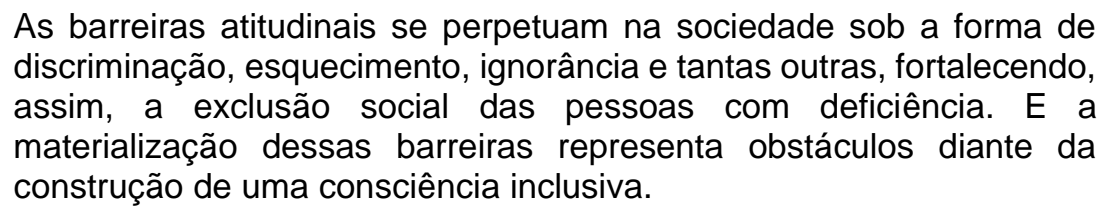

Já as barreiras sociais se referem aos processos de inclusão/exclusão social de grupos ou categorias de pessoas, especialmente no que se refere às "chamadas "minorias", como grupos étnicos, homossexuais, pessoas com deficiência e outros" (GARCIA, 2012).

Gráfico 7: Caso enfrente barreira(s),esta(s) o faz(em) sentir que é excluído?

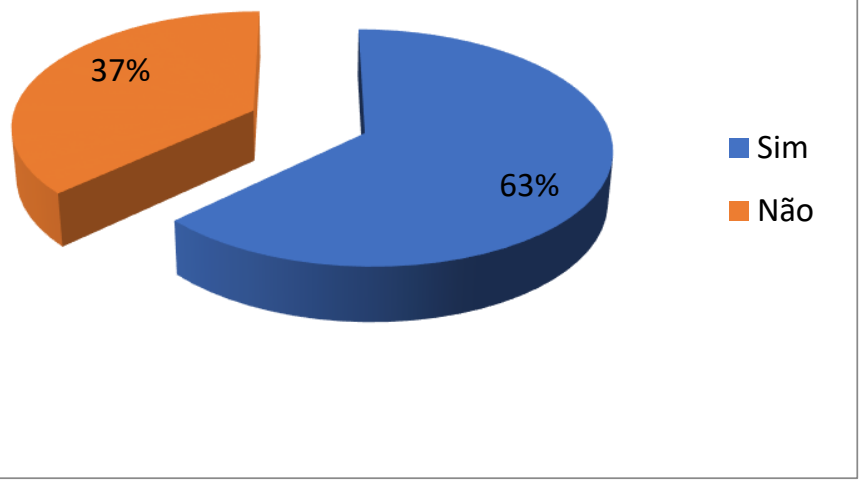

Fonte: Dados da pesquisa

Sobre esse questionamento a maioria dos alunos (63\%) respondeu que sim e $3 \%$ disseram que não se sentem excluídos diante desses tipos de barreiras. 
Os que responderam que sim apontaram algumas sugestões para que essas barreiras sejam eliminadas tais como: equipar a escola em termos materiais e pessoais, melhorar a interação e o respeito entre as pessoas, abrir possibilidades para que as pessoas conheçam melhor sobre os tipos de deficiência.

\section{Análise do questionário dos professores}

Aos professores foi aplicado um questionário com questões abertas. Foram questionados quanto: ao tempo em que atuam com alunos com tem necessidades especiais, quanto às dificuldades enfrentadas, sobre a interferência da deficiência no processo ensino-aprendizagem e os problemas de acessibilidade existentes na escola.

Participaram da pesquisa cinco professores que atuam com os alunos entrevistados. Sobre o tempo de atuação com esses alunos todos eles já ministram aulas para a inclusão há mais de cinco anos.

Sobre as principais dificuldades enfrentadas pelos professores as respostas em comum foram: pouca oferta de formação continuada, apoio itinerante que dificulta uma atenção individualizada para os alunos, falta de material e falta de envolvimento da família.

No que diz respeito à relação entre deficiência física de modo específico e aprendizagem a maioria dos professores não concordam. O que falta segundo eles é maior investimento para que os docentes possam de fato se dedicar a esses discentes e atender suas necessidades.

Acerca dos problemas de acessibilidade, os professores não os apontaram, mas apenas citaram a necessidades de melhorar as rampas de acesso, a adequação aos banheiros dos alunos e instalações onde se fizeram necessário como, por exemplo, no pátio da escola.

Para os docentes entrevistados a escola pode ser tornar acessível buscando estratégias e mecanismos contando com a sociedade e com o próprio Estado para isso. Tornar-se acessível segundo os professores é abrir-se para o outro e mesmo diante de alguma lacuna em termos materiais, buscar meios de interação e de partilha com o outro. 


\section{CONCLUSÃO}

A escola em análise possui alunos com todos os tipos de deficiências e tal fato é positivo, porque mostra que a própria escola é laboratório vivo para se vivenciar a inclusão.

No que tange a inclusão de pessoas com deficiência física, será necessário que a escola viabilize a acessibilidade e rompa com barreiras físicas, utilizando metodologias que favoreçam a plena participação destes alunos e, sobretudo, abra possibilidades para que estes mostrem suas potencialidades, apesar das limitações físicas ou intelectuais.

A pesquisa mostra que a inclusão de alunos com deficiência no contexto escolar está passando por um processo de reestruturação cujo principal avanço é a tomada de consciência por parte do professor de que é necessário acolher a todos sem distinção, principalmente quando se trata de uma criança com deficiência intelectual e que está indo à escola pela primeira vez.

Nesse sentido, foi ressaltado que a legislação também contribuiu de maneira considerável, pois, fez a revisão de leis e pareceres voltados para esta modalidade educativa, além de apresentar outras mudanças necessárias para que esta inclusão ocorra de fato.

As mudanças que estão ocorrendo no contexto educacional exigem um professor engajado com elas, assim como a efetividade e solidez de políticas públicas consistentes e estruturantes de novas práticas que estejam de acordo com as demandas da sociedade contemporânea e forneçam o suporte necessário para a construção de um mundo mais justo, fraterno e inclusivo.

Nessa perspectiva as tecnologias assistivas desempenham papel de fundamental importância, pois, muito mais que recursos e estratégias, elas permitem a construção de significados, ao mesmo tempo em que propicia a independência do aluno com deficiência, incluindo-o junto aos demais.

Os objetivos e hipóteses do estudo foram atendidos. Tais necessidades estão traduzidas nas respostas dos entrevistados que não somente afirmam a existência destas barreiras, como também confirmam que as mesmas acabam 
prejudicando seu processo de aprendizagem. Associando estas vozes com o referencial apresentado, verifica-se que no Brasil os entraves para a efetivação de uma educação inclusiva de qualidade encontram-se não somente nos espaços escolares, já que em toda a sociedade é possível verificar as dificuldades encontradas pelos deficientes físicos para se locomoverem de um lugar para outro.

Desta forma, sugere-se a criação de políticas públicas efetivas que estejam realmente voltadas para tais necessidades, pois, sabe-se que existem muitos documentos que já foram analisados que serviram de suporte para a elaboração destas políticas, no entanto, muitas delas ainda estão apenas no papel, como por exemplo, a própria Lei de Diretrizes e Bases da Educação Nacional n. 9394/96 que garante o acesso de todos os alunos a uma educação pública de qualidade. Contudo, o que se contrapõe a este dispositivo legal e demais legislações é exatamente a morosidade para que os recursos cheguem às escolas para que as mudanças ocorram em todos os níveis.

Outra sugestão seria a adaptação física das escolas e das universidades viabilizando o acesso de pessoas com deficiência. Além disso, ressalta-se a importância da contratação e/ou realização de concursos de profissionais capacitados para atuar com estes alunos, tendo como respaldo as tecnologias assistivas que são imprescindíveis para o acesso ao conhecimento e a ampliação do que já foi sistematizado ao longo da escolarização de cada aluno. 


\section{REFERÊNCIAS}

CHIAVENATO, Idalberto. Recursos Humanos. O capital humano das organizações; São Paulo, editora Campus, 2009.

HALL DMB. Commentary. Arch Dis Child 1995.

JONSSON, Ture. De lá educacion tradicional a La inclusiva: um câmbio de prácticas. In Marcha, Bruzelas, Revista Presença Pedagógica n. maio, p. 6, 1994.

MACIEL, Maria Regina Cazzaniga. Portadores de deficiência: a questão da inclusão social. São Paulo Perspec. [online]. 2000, vol.14, n.2, pp.51-56. ISSN 0102-8839.

MARTINS, J. A.; BARSAGLINI, R. A. Aspectos da identidade na experiência da deficiência física: um olhar socioantropológico. Interface - Comunic., Saude, Educ, 2011. Disponível em < www.scielo.br/pdf/icse/2010nahead/aop4110.pdf> Acesso em 17 set. 2016.

ROSA, B. Aprendendo na diversidade: Implicações educativas. Foz do Iguaçu: 2003.

SALAMANCA, Declaração de. Conferência mundial sobre necessidades educativas especiais. Salamanca, 7 a 10 de junho de 1994. Paris: Éditions du Seuil, 1997.

SASSAKI, Romeu Kazumi. Inclusão: construindo uma sociedade para todos. Rio de Janeiro, WVA, 1997.

SIQUEIRA, Fernando Carlos Vinholes et al. Barreiras arquitetônicas a idosos e portadores de deficiência física: um estudo epidemiológico da estrutura física das unidades básicas de saúde em sete estados do Brasil. Ciênc. saúde coletiva [online]. 2009, vol.14, n.1.

STAINBACK, Susan e STAINBACK, Wilian. Inclusão: Um Guia para Educadores. Porto Alegre: Artes Médicas Sul, 1999.

CHIAVENATO, Idalberto. Recursos Humanos. O capital humano das organizações; São Paulo, editora Campus, 2009.

HALL DMB. Commentary. Arch Dis Child 1995.

JONSSON, Ture. De lá educacion tradicional a La inclusiva: um câmbio de prácticas. In Marcha, Bruzelas, Revista Presença Pedagógica n. maio, p. 6, 1994. 
MACIEL, Maria Regina Cazzaniga. Portadores de deficiência: a questão da inclusão social. São Paulo Perspec. [online]. 2000, vol.14, n.2, pp.51-56. ISSN 0102-8839.

MARTINS, J. A.; BARSAGLINI, R. A. Aspectos da identidade na experiência da deficiência física: um olhar socioantropológico. Interface - Comunic., Saude, Educ, 2011. Disponível em < www.scielo.br/pdf/icse/2010nahead/aop4110.pdf> Acesso em 17 set. 2016.

ROSA, B. Aprendendo na diversidade: Implicações educativas. Foz do Iguaçu: 2003.

SALAMANCA, Declaração de. Conferência mundial sobre necessidades educativas especiais. Salamanca, 7 a 10 de junho de 1994. Paris: Éditions du Seuil, 1997.

SASSAKI, Romeu Kazumi. Inclusão: construindo uma sociedade para todos. Rio de Janeiro, WVA, 1997.

SIQUEIRA, Fernando Carlos Vinholes et al. Barreiras arquitetônicas a idosos e portadores de deficiência física: um estudo epidemiológico da estrutura física das unidades básicas de saúde em sete estados do Brasil. Ciênc. saúde coletiva [online]. 2009, vol.14, n.1.

STAINBACK, Susan e STAINBACK, Wilian. Inclusão: Um Guia para Educadores. Porto Alegre: Artes Médicas Sul, 1999. 
ANEXOS

\section{Anexo 1: Questionário aplicado com entrevistada com necessidade educativa especial}

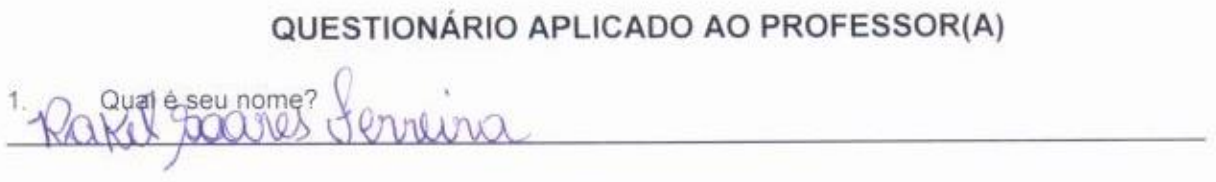

2. Há quanto tempo atua com alunos que têm necessidades educativas especiais? $E$ qual a a sua

formaçäo e funçấ na Unidade Escolaj?

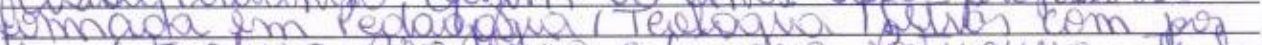

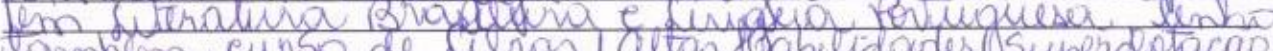

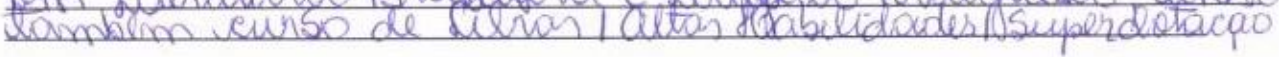

3. Quais săo as principais dificuldades para ofertar uma, educaçåo - inclusiva de qualidade? if fato de que os veyrsos na area unclusciva

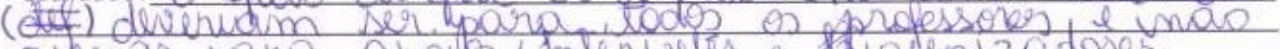

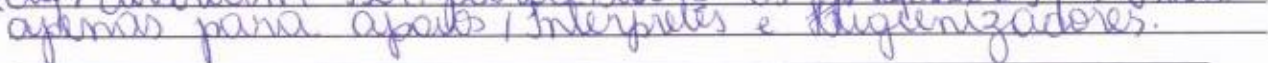

3. Em relaçăo à deficiência física de modo especifico, você concorda que a deficiència interfere na

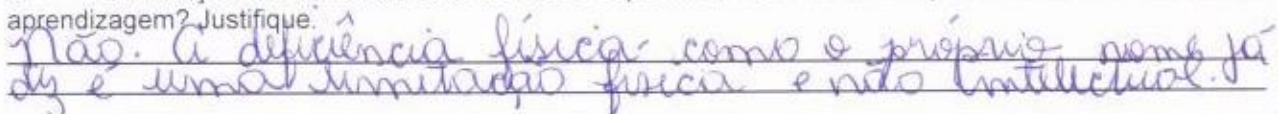

4. Quanto aos problemas de acessibilidade, quais deles prejudicam mais o acesso do aluno na

escola e na sociedade? deficiente físies, é, a própria estruntura

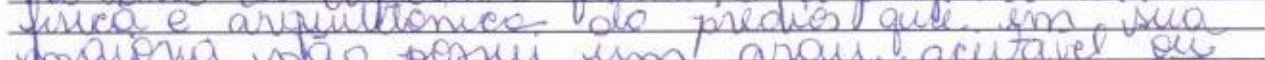

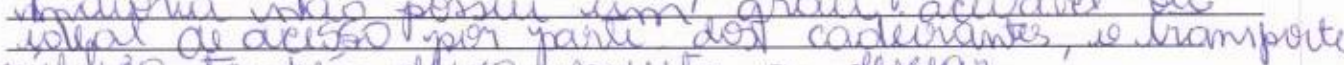
pul hico toumberm dexa muto a desejar.

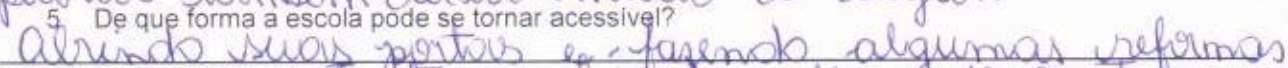

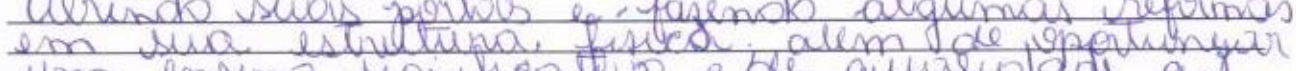

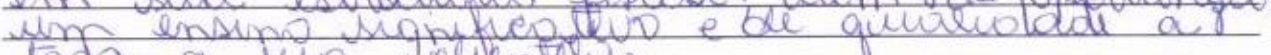
coda a sia jelientels.

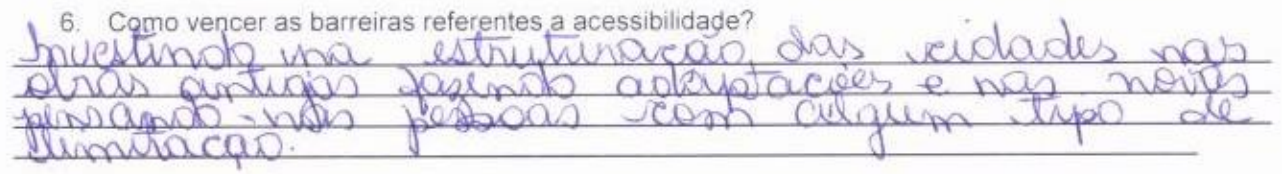




\section{Anexo 2: Carta de Goiânia}

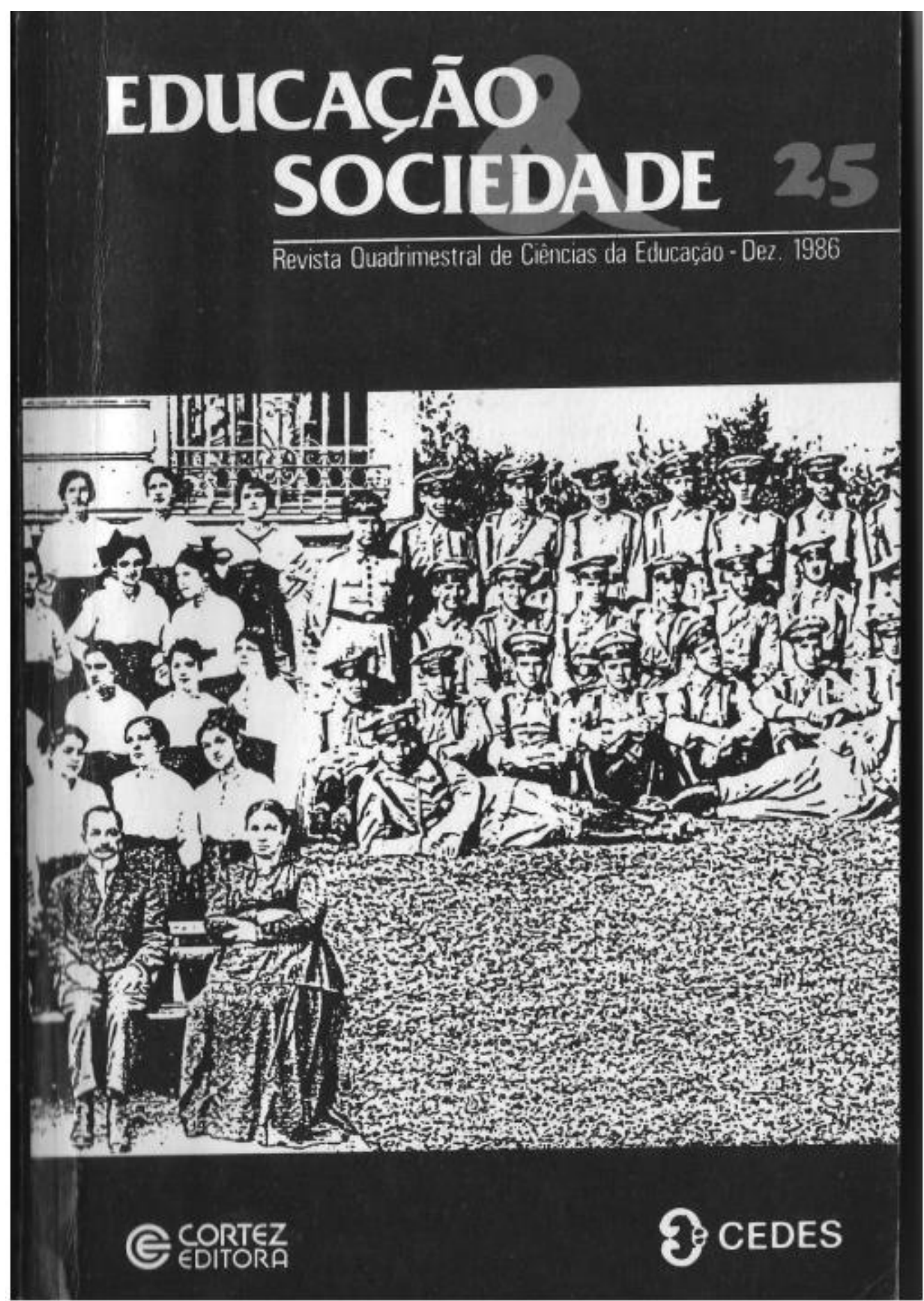


20. O Estado assegurará formas democráticas de participaçẫo e mecanismos que garantam o cumprimento e o controle social efetivo das suas obrigaçōes referentes à educação pública, gratuita e de boa qualidade em todos os niveis de ensino.

21. Fica mantido o disposto pela Emenda Calmon (EC 24, $\S 4 .^{\circ}$ do art. 176 da atual Constituição), assim como pelas Emendas Pas: sos Porto (EC 23) e Irajá Rodrigues (EC 27) e a lei estabelecerá sanções jurídicas e administrativas no caso do não-cumprimento destes dispositivos.

Os educadores presentes à IV Conferência Brasileira de Educação consideram indispensável que seja elaborada uma nova lei de diretrizes e bases da educaçăo nacional, a partir dos princípios inscritos na Constituiçāo.

Consideram, outrossim, essencial sua participação, através das entidades de representaçāo na área, tanto na elaboração da Constituição, quanto da lei acima referida.

Consideram, ainda, que devem ser mobilizados todos os recur sos no sentido de tornar público este posicionamento e de conclamar os candidatos dos diversos partidos à Constituinte, para a de fesa dos principios aqui enunciados.

Goiânia, 5 de setembro de 1986 
